удК681.3

\title{
РАЗРАБОТКА И ПРИМЕНЕНИЕ СТАЦИОНАРНОГО СКВАЖИННОГО ПРИБОРА В СИСТЕМЕ УПРАВЛЕНИЯ ПРОЦЕССОМ НЕФТЕДОБЫЧИ
}

\author{
Алаева Наталья Николаевна', \\ nalaeva@yandex.ru \\ Томус Юрий Борисович1, \\ tjub123@rambler.ru \\ Тугашова Лариса Геннадьевна ${ }^{1}$, \\ tugashowa.agni@yandex.ru \\ 1 Альметьевский государственный нефтяной институт, \\ Россия, 423450, г. Альметьевск, ул. Ленина, 2.
}

\begin{abstract}
Актуальность исследования заключается в получении достоверных измеренных технологических параметров (как минимум давления и плотности добываемой продукции) в скважине, полученных в режиме реального времени, для качественного управления нефртедобывающей скважиной и повышения эфффективности ее эксплуатации.

Цель: разработка стационарного скважинного прибора для измерения давления на приеме и выкиде насоса, внутри насоснокомпрессорных труб и межтрубного пространства нефтедобывающей скважины; составление математической модели получения необходимых технологических параметров для решения основных задач при добыче нефрти; применение стационарного скважинного прибора в предлагаемой системе управления процессом нефтедобычи.

объект - нефтедобывающая скважина.

Методы: моделирование и оценка работы предлагаемой системы управления процессом нефтедобычи с применением разработанного стационарного скважинного прибора в программе Matlab/Simulink.

Результаты. Разработан стационарный скважинный прибор для измерения давления на приеме и выкиде насоса, внутри НКТ и межтрубного пространства скважины и показана его конструкция; представлена математическая модель получения необходимых технологических параметров для решения основных задач при добыче нефрти; предложена система управления с применением разработанного прибора; поставлена и решена задача создания эфрфективной системы управления процессом нефтедобычи.

Выводы. Получен положительный результат при моделировании системы управления процессом нефтедобычи с применением разработанного скважинного прибора для измерения давления в нескольких контрольных точках ствола нефртедобывающей скважины в программе Matlab/Simulink. Реализация разработанного стационарного скважинного прибора в предлагаемой системе управления процессом нефтедобычи обеспечивает точность и быстродействие вывода скважины на стационарньй режим работы, его стабилизацию и увеличение отбора добываемой продукции.
\end{abstract}

\section{Ключевые слова:}

Нефтедобывающая скважина, измерение давления, определение технологических параметров, моделирование системы управления, процесс нефтедобьчи.

\section{Введение}

Нефтяные компании в России и в мире стремятся к повышению эффективности контроля разработки нефтегазовых месторождений. Это требует непрерывного и достоверного получения данных о параметрах добываемой жидкости внутри скважины скорости движения компонентов, перепаде давления, структуре потоков и их составе на основных участках скважины: забой-приём насоса, межтрубное пространство, насосно-компрессорные трубы (НКТ), насос, наземная трубопроводная система. Данная задача представляет как экономический, так и научный интерес. Точность принимаемых решений по управлению динамикой изменения добычи напрямую определяется необходимым и достаточным количеством и качеством получаемой информации.

Последние тенденции развития информационных технологий в области нефтедобычи требуют знания измеренных параметров в скважине, полученных в режиме реального времени, с целью эффективного управления нефтедобывающей скважиной и повышения ее производительности $[1,2]$.
Для измерения обводненности продукции скважин, как правило, используют пробоотборники или влагомеры, которые устанавливают на поверхности [3]. В целях качественного управления режимом работы скважины по измеренным значениям обводненности неправильно использовать измерения, осуществляемые на поверхности, поскольку единый поток нефти, газа и воды, выходящий из пласта в ствол скважины меняет свою структуру от забоя до устья. Следовательно, плотность потока, выходящего из пласта, отличается от плотности потока в скважине, и измерения обводненности продукции скважин на поверхности будут недостоверными $[4,5]$.

Измерения технологических параметров в нефтедобывающих скважинах часто бывают технически невыполнимы. В связи с этим прибегают к косвенным методам получения необходимых технологических параметров [6, 7]. Например, давление на приеме насоса, забойное давление для скважин со штанговым глубинным насосом (ШГН) можно определить по динамограмме [8]. Априори любые расчетные методы характеризуются большой погрешностью, что указывает на последующий некорректный выбор режима 
работы добывающей скважины или принятие неверных решений по управлению процессом нефтедобычи.

Существующие погружные телеметрические системы (ТМС), используемые в нефтедобывающих скважинах с электроцентробежным насосом (ЭЦН), измеряют в основном давление на приеме глубинного насоса. Для эффективного управления процессом нефтедобычи этого недостаточно. В период вывода скважины на стационарный режим и его дальнейшей стабилизации необходимо дополнительно знать давление в межтрубном пространстве скважины и на выкиде глубинного насоса, причем в нескольких точках и с возможностью определения плотности жидкости на соответствующих участках ствола нефтедобывающей скважины.

Одной из актуальных проблем современной нефтедобывающей промышленности является создание эффективных систем управления процессом нефтедобычи с целью повышения производительности скважин и, следовательно, эффективности эксплуатации месторождений [9-18].

Анализ существующих систем управления процессом нефтедобычи показал, что применяемые системы управления не являются достаточно эффективными в условиях изменения технологических параметров в стволе добывающей скважины. Изменения состава и скорости движения нефтеводогазовой (НВГ) смеси на различных участках нефтедобывающей скважины при различном водогазосодержании свидетельствуют о необходимости измерения давления, температуры, плотности, скорости движения, уровня жидкости в контрольных точках ствола нефтедобывающей скважины. Контрольные точки - это точки, в которых измеренная информация максимально уменьшает неопределённость расчётных параметров. Такими точками являются приём и выкид глубинного насоса, где, с одной стороны, можно контролировать приток жидкости из пласта и параметры межтрубного пространства, а с другой - противодавление или нагрузку насоса и её составляющих (гидростатику, инерцию, трение, влияние газа, вязкости и т. д. подъёмника). Другими словами, необходимым и достаточным условием информационного обеспечения процесса добычи является установка дистанционных, стационарных манометров и манометрических плотномеров на приеме и выкиде глубинного насоса, т. е. внутри НКТ и межтрубного пространства нефтедобывающей скважины. Это требует разработки новых недорогостоящих стационарных скважинных приборов для измерения давления в соответствующих точках ствола скважины.

Авторами разработано устройство для измерения давления внутри НКТ и межтрубного пространства нефтедобывающей скважины [19] с возможностью установки его в нескольких точках ствола скважины. Устройство состоит из скважинной камеры - 1 в виде НКТ с резьбовыми соединениями - 2 на концах и двухдатчикового манометра - 3, закрепленного своим цилиндрическим выступом - 21 «заподлицо» с внутренней стенкой - 20 НКТ так, что один датчик давления - 4 гидравлически связан с пространством внутри НКТ, а другой - 5 - с межтрубным пространством скважины (рис. 1). При этом в НКТ выполнено цилиндрическое отверстие, в которое герметично с помощью уплотнения - 15 помещен цилиндрический выступ корпуса дистанционного глубинного двухдатчикового манометра - 3 с поперечным НКТ сквозным отверстием, в котором соосно расположены две одинаковые мембраны с кремниевыми тензометрами датчиками давления - 4, 5, одна из которых воспринимает давление с внутренней стороны НКТ, а другая - с внешней, причем внутренняя полость корпуса защищена от внешней среды уплотнениями в виде резиновых колец на внешней поверхности мембран, а перемещение мембран относительно друг друга ограничено с внешней стороны крышкой -7 и стальным пружинным кольцом - 6, а изнутри - выступами в корпусе (уменьшением диаметра сквозного отверстия относительно диаметра мембран).

Выводы тензометров подключены к электронной обрабатывающей схеме -8 внутри корпуса - 16 дистанционного глубинного двухдатчикового манометpa - 3, герметично закрытой кожухом - 9, имеющего в продольном НКТ направлении сквозные отверстия для прохождения с герметизацией элементами - 17 , 18,19 в кожухе - 9 и элементами - 12, 13, 14 в корпусе -3 входного - 10 и выходного - 11 провода питания и связи, а в поперечном НКТ направлении сквозные отверстия для установки крепежных винтов, под которые в НКТ выполнены несквозные резьбовые отверстия.

На рис. 2 изображена схема установки двух устройств для одновременного измерения давления вне и внутри НКТ, расположенных на расстоянии 10 м друг от друга (т. е. на одной НКТ) и соединенных между собой и с поверхностью одножильным проводом питания и связи.

Каждое устройство содержит дистанционный глубинный двухдатчиковый манометр, в котором соосно расположены две одинаковые мембраны с кремниевыми тензометрами - датчиками давления, одна из которых воспринимает давление с внутренней стороны НКТ $P_{1}^{\prime}$ и $P_{2}^{\prime}$, а другая - с внешней $P_{1}$ и $P_{2}$.

Предлагаемое устройство позволяет устанавливать на колонне НКТ несколько датчиков давления подряд (рис. 2) и размещать эти датчики с заданным сдвигом по глубине. Установка устройства не изменяет геометрию гидравлического канала внутри НКТ, как показано на рис. 1, где видно, что внутренняя стенка - 20 НКТ свободна от каких-либо деталей устройства. Это дает возможность применять предлагаемое устройство во всех нефтяных добывающих скважинах, в том числе и в скважинах с ШГН.

По измеренным давлениям в контрольных точках скважины $P_{1}, P_{2}, P_{1}^{\prime}, P_{2}^{\prime}$ можно вычислить следующие технологические параметры:

- плотность жидкости на уровне приёма насоса

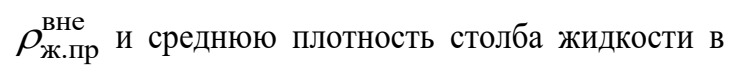
межтрубном пространстве $\rho_{\text {вне }}^{\text {вн }}$ 


$$
\rho_{\text {ж.пр }}^{\text {вне }}=\frac{P_{1}-P_{2}}{g \cdot L}, \rho_{\text {же }}^{\text {вне }}=\frac{P_{1}}{g \cdot H_{\text {дин }}},
$$

где $P_{1}$ и $P_{2}$ - давление в двух точках внутри межтрубного пространства, МПа; $g$ - ускорение свободного падения, м/ $\mathrm{c}^{2} ; L$ - расстояние между датчиками давления, 10 м; $H_{\text {дин }}-$ динамический уровень, м.

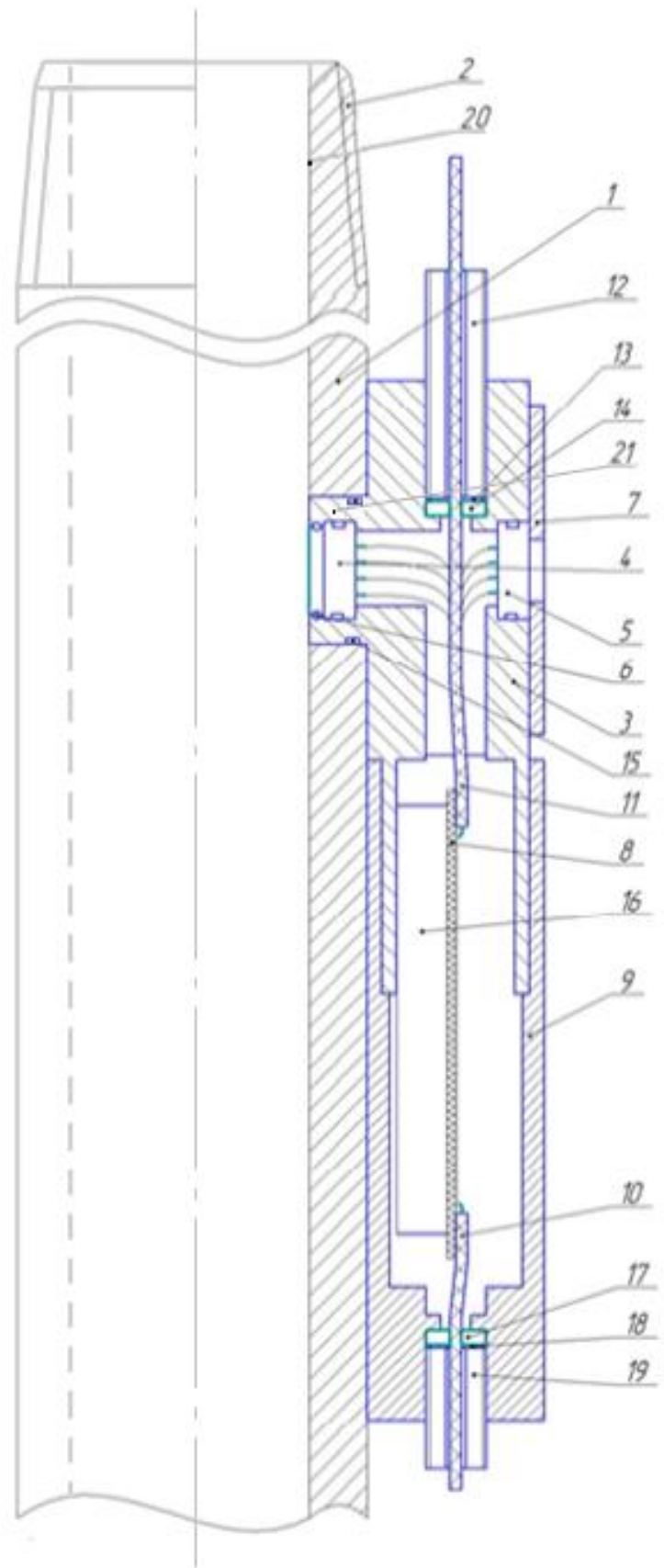

Pис. 1. Устройство для одновременного измерения давления вне и внутри НКТ

Fig. 1. Device for simultaneous measurement of pressure outside and inside the tubing

- плотность жидкости на уровне выкида насоса $\rho_{\text {ж.вык }}^{\text {вну }}$ и среднюю плотность столба жидкости внутри НКТ $\rho_{\text {вну }}^{\text {вну }}$

$$
\rho_{\text {ж.вык }}^{\text {вну }}=\frac{P_{1}^{\prime}-P_{2}^{\prime}}{g \cdot L}, \rho_{\text {ж }}^{\text {вну }}=\frac{P_{1}^{\prime}}{g \cdot H_{\text {сп }}},
$$

где $P_{1}^{\prime}$ и $P_{2}^{\prime}$ - давление в двух точках внутри НКТ, МПа; $g$ - ускорение свободного падения, м/ $\mathrm{c}^{2} ; L-$ расстояние между датчиками давления, 10 м; $H_{\text {сп }}$ - глубина спуска насоса, м.

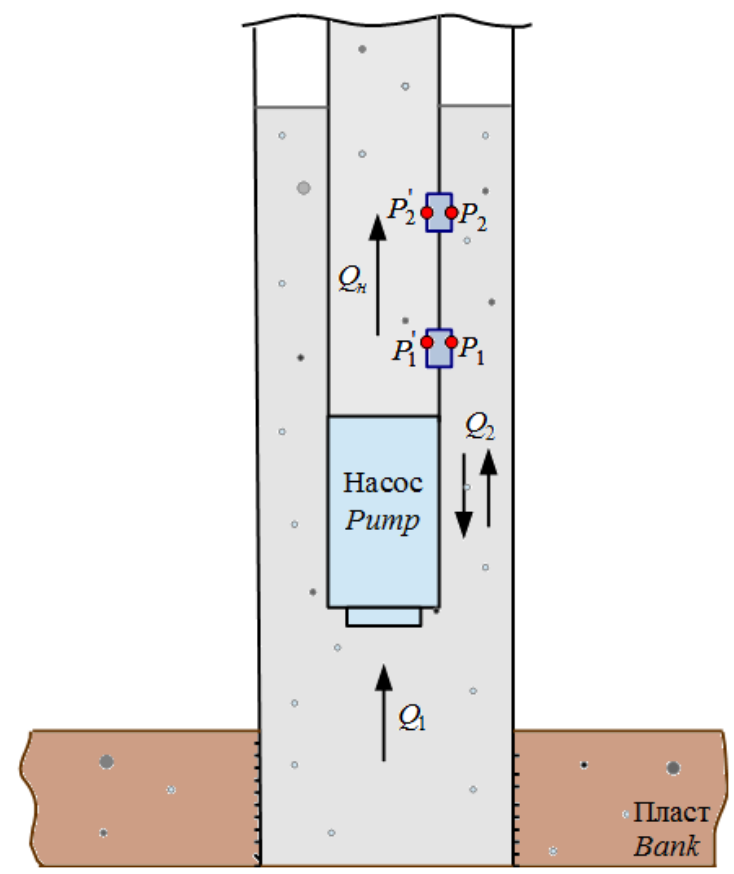

Pис. 2. Схема установки двух устройств в нефтедобывающей скважине для одновременного измерения давления вне и внутри НКТ. $Q_{1}$ - приток жидкости из пласта; $Q_{2}-$ поток жидкости из межтрубного пространства; $Q_{H}-$ приток жидкости в НКТ

Fig. 2. Diagram of installation of two devices in an oil well for simultaneous measurement of pressure outside and inside the tubing. $Q_{1}$ is the fluid flow from the reservoir; $Q_{2}$ is the fluid flow from the annulus; $Q_{H}$ is the fluid flow in the tubing

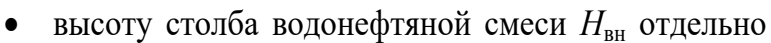
на участке от выкида насоса до уровня жидкости в НКТ, где давление становится меньше давления насыщения нефти газом $P_{\text {нас }}$

$$
H_{\text {вн }}=\frac{P_{\text {нас }}}{g \cdot \rho_{\text {ж.вык }}^{\text {вну }}},
$$

а также высоту столба водогазонефтяной смеси $H_{\text {вгн }}$ при известной глубине спуска насоса $H_{\text {сп }}$

$$
H_{\text {вгн }}=H_{\text {сп }}-H_{\text {вн }},
$$

уровни жидкости (нефти) в межтрубном пространстве

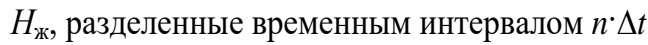

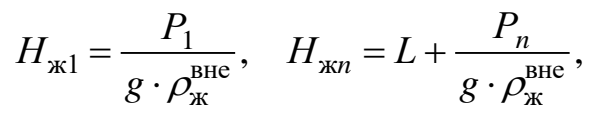

где $P_{1}$ и $P_{n}-$ измеренное давление (отсчёты, разделённые одним или несколькими интервалами дискре- 
тизации) в двух точках внутри межтрубного пространства скважины, МПа; $\rho_{ж}^{\text {вне }}-$ средняя плотность столба жидкости в межтрубном пространстве, кг $/ \mathrm{M}^{3}$; $g$ - ускорение свободного падения, м/ $\mathrm{c}^{2} ; L$ - расстояние между датчиками давления, $10 \mathrm{~m} ; n=1,2,3, \ldots$, $n_{\max }=\frac{t_{\max }}{\Delta t}-$ временной интервал дискретизации; $t_{\max }-$ время, при котором $P_{n}=$ const, $\mathrm{c} ; \Delta t-$ интервал дискретизации при измерении давления, сек.

- расход жидкости, пришедшей в межтрубное пространство (или откачанной из него)

$$
Q_{2}=V_{\text {ж }} \cdot S=V_{\text {ж }} \cdot \pi \cdot \frac{D^{2}-d^{2}}{4},
$$

где $V_{\text {ж }}=\frac{H_{\text {ж1 }}-H_{\text {жn }}}{n \cdot \Delta t}-$ скорость движения жидкости в межтрубном пространстве, м/с; $S$ - площадь сечения межтрубного пространства, м $^{2} ; D$ - диаметр обсадной колонны, м; $d$ - диаметр НКТ, м.

Практика эксплуатации скважин показывает, что для повышения эффективности нефтеизвлечения необходимо управлять режимом работы насоса при ограничениях со стороны давления жидкости (динамического уровня) [20]. Известно, что процесс добычи существенно зависит от давления в скважине, величина которого при эксплуатации скважины может по разным причинам изменяться. Наиболее целесообразным способом регулирования является изменение скорости вращения насоса (на примере электроцентробежного насоса (ЭЦН)). Поэтому гидравлическую систему «скважина-насос» можно считать объектом управления. При этом разработка эффективных систем управления процессом нефтедобычи по критерию максимального отбора продукции скважин должна быть направлена на использование минимального количества непосредственно измеряемых параметров, необходимых и достаточных для качественного управления системой.

На рис. 3 представлена структура предлагаемой системы управления процессом нефтедобычи с применением разработанного устройства для измерения давления в контрольных точках скважины.

На основании предложенной структуры системы управления с применением разработанного устройства для измерения давления в контрольных точках скважины авторами была разработана и исследована ее модель (по данным реальной скважины с ЭЦН Ромашкинского месторождения), приведенная на рис. 4.

При моделировании системы управления осуществляется математическая зависимость основных параметров $\left(H_{\text {дин }}, Q_{2}, Q_{1}, Q_{\mathrm{H}}\right)$ от изменения давлений в контрольных точках скважины $P_{1}, P_{2}, P_{1}^{\prime}, P_{2}^{\prime}$.

Динамический уровень жидкости $H_{\text {дин }}$ зависит от давления на выкиде насоса $P_{1}^{\prime}$ и средней плотности столба жидкости в межтрубном пространстве $\rho_{ж}^{\text {вне }}$, определяемой по давлениям $P_{1}$ и $P_{2}$ :

$$
H_{\text {дин }}=\frac{P_{1}^{\prime}}{\rho_{\text {ж }}^{\text {вне }} \cdot g}-H,
$$

где $H$ - напор насоса, определяемый по напорной характеристике $H=f\left(Q_{\mathrm{H}}\right)$, м.

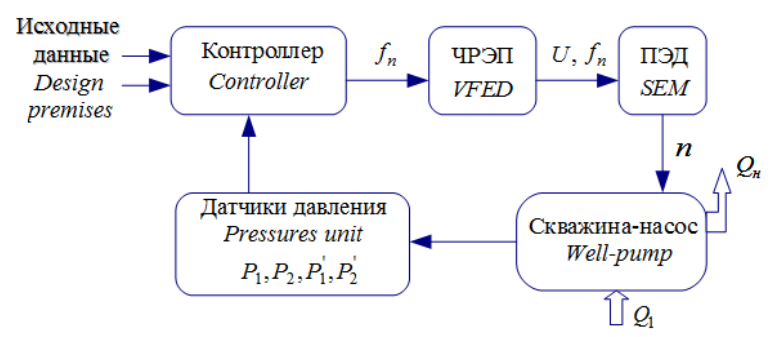

Pис. 3. Структура системы управления с применением разработанного устройства для измерения давления в контрольных точках скважинь: ЧРЭПчастотно-регулируемый электропривод; ПЭД погружной электродвигатель; $U u f_{n}$ - напряжение и частота тока ПЭД; $n$ - частота вращения насоса

Fig. 3. Structure of the control system with the use of the developed device for measuring pressure at the control points of the well: VFED is the variablefrequency electric drive; SEM is the submersible electric motor; $U$ and $f_{n}$ are the voltage and frequency of the current of the SEM; $n$ is the pump rotation frequency

Изменение потока жидкости из межтрубного пространства $Q_{2}$ зависит от изменения динамического уровня

$$
Q_{2}=S \cdot \frac{d H_{\text {дин }}}{d t},
$$

где $S$ - площадь сечения межтрубного пространства, $\mathrm{M}^{2}$.

Приток жидкости из пласта $Q_{1}$ определяется по следующей формуле:

$$
\begin{gathered}
Q_{1}=K_{\text {пр }}\left(P_{\text {пл }}-P_{\text {заб }}\right) \cdot\left(1-e^{-\alpha t}\right)= \\
=\left[\begin{array}{l}
K_{\text {пр }} \cdot P_{\text {пл }}-K_{\text {пр }} \times \\
\times\left(g \cdot \rho_{\text {ж.пр }}^{\text {вне }} \cdot\left(H_{\mathrm{c}}-H_{\text {сп }}\right)+P_{1}\right)
\end{array}\right] \cdot\left(1-e^{-\alpha t}\right),
\end{gathered}
$$

где $K_{\text {пр }}$ - коэффициент продуктивности, м³/(сут·МПа); $P_{\text {пл }}-$ пластовое давление, МПа; $P_{\text {заб }}-$ забойное давление, МПа; $\alpha=\left(\frac{K_{\text {пр }} \cdot g \cdot \rho_{\text {ж.пр }}^{\text {вне }}}{S}\right), \mathrm{c}^{-1} ; t-$ реальное

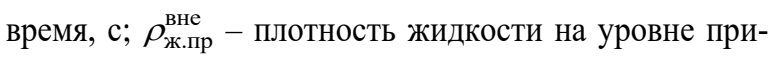
ёма насоса, определяемая по давлению на приеме насоса $P_{1}$ и давлению $P_{2}$ в контрольной точке межтрубного пространства, кг/м ${ }^{3} ; H_{c}$ - глубина скважины, м; $H_{\text {сп }}$ - глубина спуска насоса, м.

Поток жидкости в НКТ $Q_{\mathrm{H}}$ представляет собой два объединенных потока $Q_{1}$ - приток жидкости из пласта и $Q_{2}$ - поток жидкости межтрубья (рис. 2), т. е.

$$
Q_{\mathrm{H}}=Q_{1} \pm Q_{2} \text {. }
$$




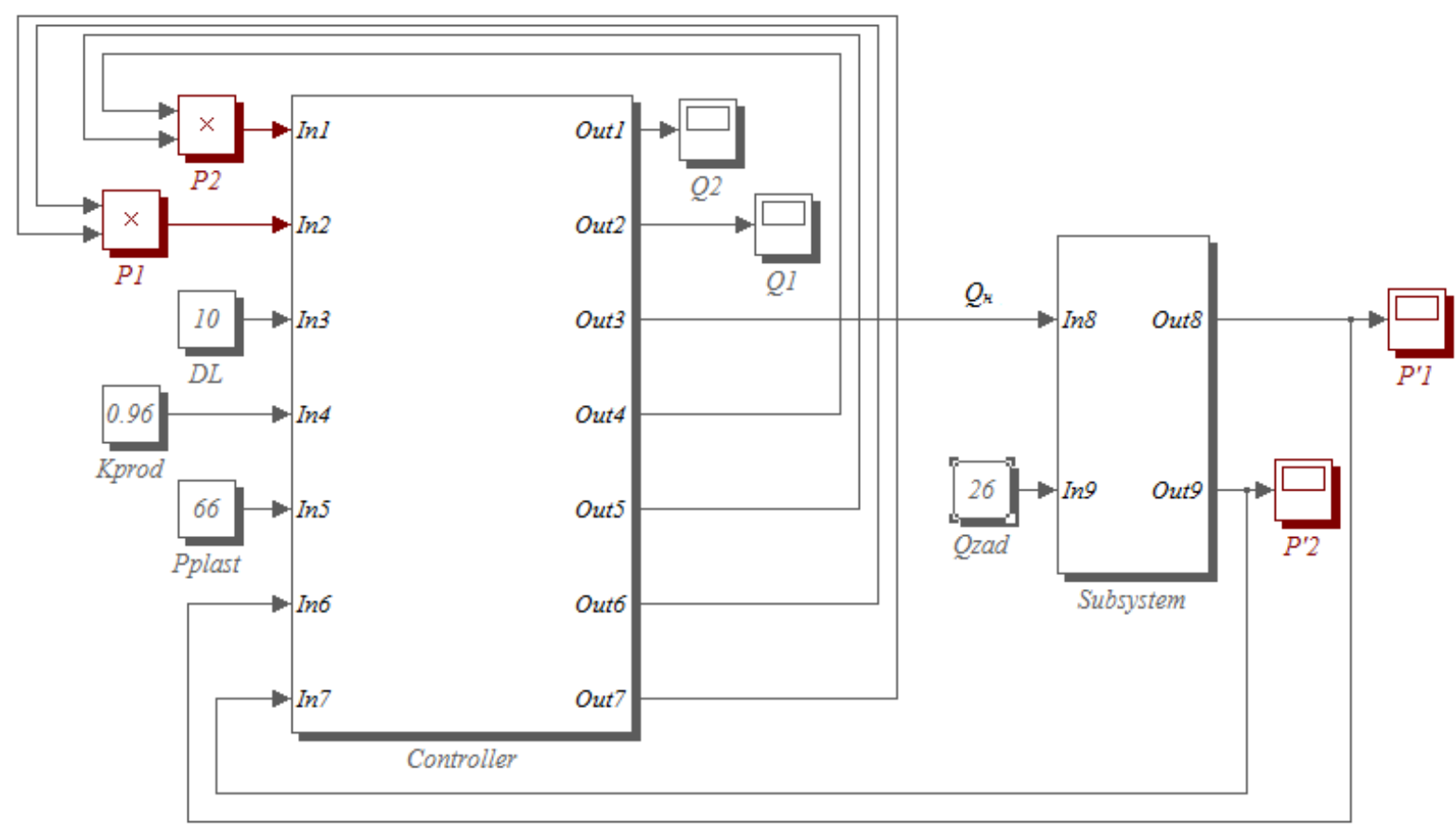

Рис. 4. Модель системы управления процессом добычи нефти с применением разработанного устройства в программе Matlab/Simulink

Fig. 4. Simulation of an oil production control system using the developed device in the Matlab/Simulink program

Экспериментальное исследование системы управления процессом нефтедобычи в программе Matlab/Simulink проводилось в 3-х режимах, отличающихся как минимум временными характеристиками их передаточных функций: 1) режим пуска насоса; 2) рабочий переходный режим (рис. 5) и 3 ) останов скважины. Приток жидкости из пласта $Q_{1}$, поток жидкости межтрубного пространства $Q_{2}$, давления в контрольных точках ствола нефтедобывающей скважины $\left(P_{1}, P_{2}, P_{1}^{\prime}, P_{2}^{\prime}\right)$ принимаем за выходные координаты объекта управления. Дебит жидкости на

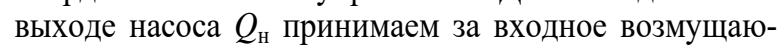
щее воздействие. Режим работы скважины считается установившимся при условии, когда $Q_{2}=0, Q_{1}=Q_{\text {н }}$ и динамический уровень жидкости постоянный $H_{\text {лин }}=$ const. Выполнение этих требований должна осуществлять система управления режимом работы скважины, чтобы обеспечить получение заданной нормы добычи жидкости, т. е. $Q_{\text {н }}$.

При моделировании на вход блока Controller поступали следующие параметры: текущие значения давлений на приеме насоса $P_{1}$ и в межтрубном пространстве $P_{2}$, текущие значения давлений на выкиде насоса $P_{1}^{\prime}$ и в НКТ $P_{2}^{\prime}$ из блока Subsystem, а также постоянные значения коэффициента продуктивности $K_{\text {пр }}$, пластовое давление $P_{\text {пл }}$, расстояние между датчиками давления $L$. В блоке Controller выполнен контроллер, реализующий алгоритм вычисления ряда технологических параметров ( $\rho_{\text {ж.пр }}^{\text {вне }}, \rho_{\text {вне }}^{\text {вн }}, \rho_{\text {ж.вык }}^{\text {вну }}$, $\left.\rho_{\text {ж }}^{\text {вну }}, H_{\text {вн }}, H_{\text {вгн }}, H_{ж}, H_{\text {дин }}, Q_{2}, Q_{1}, Q_{\text {н }}\right)$. Блоки $Q_{2}$ и $Q_{1}$ на выходе блока Controller предназначены для визуализации графиков изменения потока жидкости межтрубного пространства $Q_{2}$ и притока жидкости из пласта $Q_{1}$, соответственно.

Таблица. Параметры моделируемой скважинной системь

Table. Parameters of the simulated well system

\begin{tabular}{|c|c|c|}
\hline $\begin{array}{c}\text { Наименование, ед. изм. } \\
\text { Name, units }\end{array}$ & $\begin{array}{c}\text { Величина } \\
\text { Value }\end{array}$ & $\begin{array}{c}\text { Обозначение } \\
\text { Notation }\end{array}$ \\
\hline $\begin{array}{l}\text { Пластовое давление, атм } \\
\text { Reservoir pressure, atm }\end{array}$ & 66 & $P_{\text {пл }}$ \\
\hline $\begin{array}{l}\text { Глубина скважины, м } \\
\text { Well depth, m }\end{array}$ & 962 & $H_{\mathrm{c}}$ \\
\hline $\begin{array}{l}\text { Глубина спуска насоса, м } \\
\text { Pump depth, m }\end{array}$ & 449 & $H_{\text {сп }}$ \\
\hline $\begin{array}{l}\text { Коэффициент продуктивности, } \\
\text { м }^{3} /(\text { cyт } \cdot \text { МПа) } \\
\text { Productivity factor, } \mathrm{m}^{3} /(\text { day·MPa })\end{array}$ & 0,96 & $K_{\text {пр }}$ \\
\hline $\begin{array}{l}\text { Объёмная доля воды, ед. } \\
\text { Water cut, units }\end{array}$ & 0,85 & $W$ \\
\hline $\begin{array}{l}\text { Статический уровень, м } \\
\text { Static pressure-head level, m }\end{array}$ & 745 & $H_{\mathrm{cT}}$ \\
\hline $\begin{array}{l}\text { Площадь сечения межтрубного про- } \\
\text { странства, м² } \\
\text { Section area tubular annulus, } \mathrm{m}^{2}\end{array}$ & $4,657 \cdot 10^{-3}$ & $S$ \\
\hline \multicolumn{3}{|c|}{ Удельный вес, МПа/м/Specific gravity of, MPa/m } \\
\hline нефти/оil & $0,7 \cdot 10^{-2}$ & $\gamma_{o}$ \\
\hline воды/water & $1,067 \cdot 10^{-2}$ & $\gamma_{w}$ \\
\hline газа/gas & $0,83 \cdot 10^{-5}$ & $\gamma_{g}$ \\
\hline
\end{tabular}

Входными параметрами блока Subsystem являются: текущее значение дебита жидкости на выходе насоса $Q_{\text {н }}$ из блока Controller и заданное значение дебита жидкости $Q_{z a d}$. В блоке Subsystem, который включает в себя ЧРЭП, ПЭД и насос, осуществляется преобразование рассогласования $\Delta Q$ между текущим $Q_{\text {н }}$ и заданным $Q_{z a d}$ значениями дебита жидкости в частоту тока ПЭД, а также регулирование скорости вращения 
насоса и, соответственно, изменение напора насоса $H$, давлений внутри НКТ $P_{1}^{\prime}$ и $P_{2}^{\prime}$. Блоки $P^{\prime} 1, P^{\prime} 2$ предназначены для визуализации графиков изменения значений давления на выкиде насоса $P_{1}^{\prime}$ и в НКТ $P_{2}^{\prime}$.

По результатам исследований системы управления с применением разработанного устройства на модели выявлено, что при установке заданного значения дебита жидкости $Q_{z a d}=26 \mathrm{~m}^{3} /$ сут., близкого к минимальному для успешного запуска скважины, происходит скачкообразное увеличение $Q_{\text {н }}$ от 0 до $26 \mathrm{~m}^{3} /$ сут., при этом

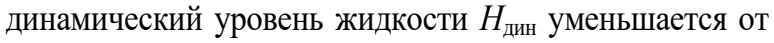
745 до 588 м за 6,94 часа и стабилизируется (рис. 5).

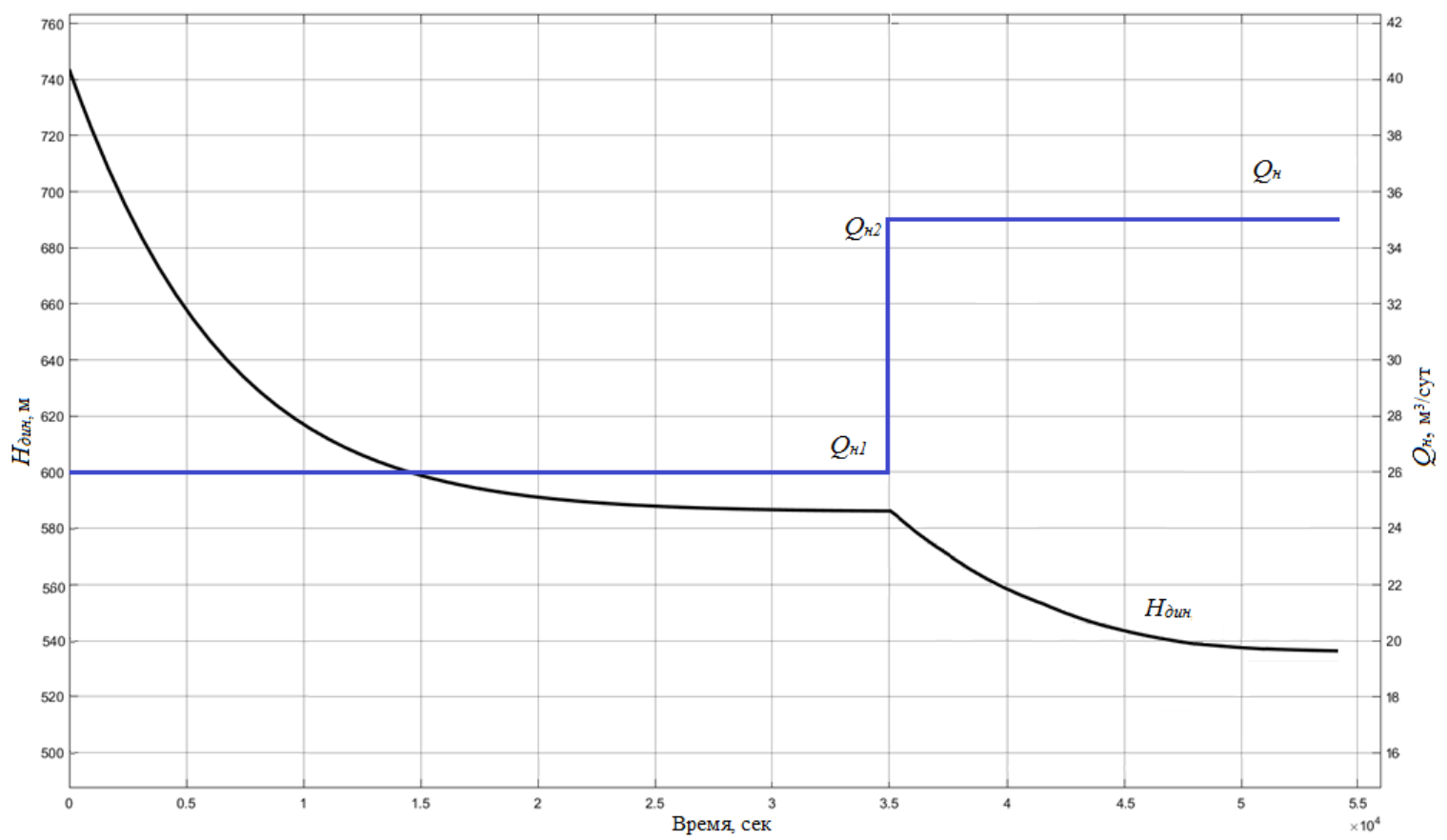

Pис. 5. Графики режима запуска и перехода в рабочий режим работы скважины

Fig. 5. Graphs of start mode and transition to operating mode of well

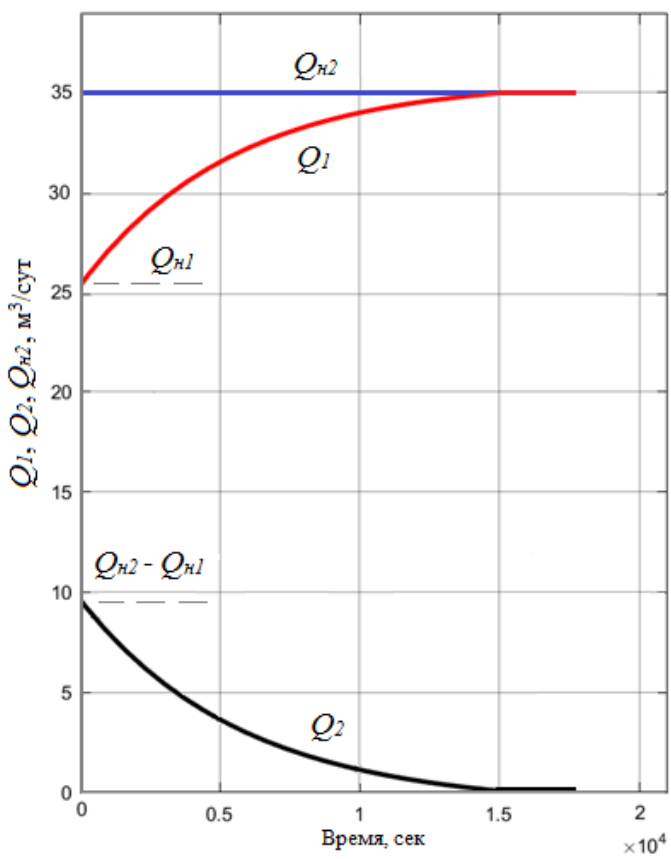

Рис. 6. Графики изменения притока жидкости из пласта $Q_{1}$ и потока жидкости из межтрубного пространства $Q_{2}$ при увеличении $Q_{н}$ oт 26 до $35 \mathrm{~m}^{3} / \mathrm{cym}$.

Fig. 6. Graphs of changes in fluid inflow from the reservoir $Q_{1}$ and in fluid flow from the annular space $Q_{2}$ at increase of $Q_{H}$ from 26 to $35 \mathrm{~m}^{3} /$ day
При установке заданного значения дебита жидкости $Q_{z a d}=35 \mathrm{~m}^{3} /$ сут., соответствующего рабочему режиму скважины, происходит скачкообразное увеличение $Q_{\text {н }}$ от $Q_{\mathrm{H} 1}=26 \mathrm{~m}^{3} /$ сут. до $Q_{\mathrm{H} 2}=35 \mathrm{~m}^{3} /$ сут. (рис. 5), при этом:

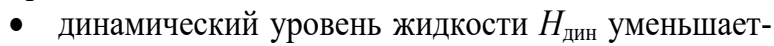
ся с 588 до 538 м за 4,17 часа и стабилизируется (рис. 5);

- $\quad$ приток жидкости из пласта $Q_{1}$ достигает значения 35 м/сут. за 4,17 часа и стабилизируется (рис. 6);

- поток жидкости из межтрубного пространства $Q_{2}$ уменьшается по экспоненте от $Q_{2}=35-26=9 \mathrm{~m}^{3} /$ сут. до нуля (рис. 6);

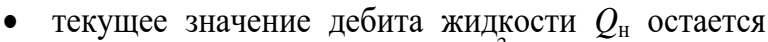
стабильным и равным $Q_{\mathrm{H} 2}=35 \mathrm{~m}^{3} /$ сут.

Разница по времени выхода на стационарный режим при запуске скважины (время переходного режима 6,94 часа) и в рабочем режиме (время переходного режима 4,17 часа) объясняется разными начальными условиями, $Q_{1}=0$ при запуске скважины и $Q_{1}=$ $26 \mathrm{~m}^{3} /$ сут. при выходе на рабочий режим.

Использование этих данных, полученных с помощью высокоточной и быстродействующей аппаратуры, системы управления с применением разработанного устройства (рис. 4) (по сравнению, например, с эхолотом) обеспечит более точный вывод нефтедобывающей скважины на необходимый режим эксплу- 
атации, причем за меньшее время, за счёт контролируемого уровня и давления в межтрубном пространстве скважины.

Отличительной особенностью предложенной модели системы управления процессом нефтедобычи является получение данных о реальных значениях давления жидкости в нескольких контрольных точках ствола скважины с одновременным расчётом её плотности и их изменения по межтрубному пространству и НКТ, которые являются исходными при решении основных задач эксплуатации нефтедобывающих скважин. Использование этих данных обеспечит контроль как стационарного ( $H_{\text {дин }}=$ const), так и динамического $H_{\text {дин }}(t)$ уровня жидкости в межтрубном пространстве скважины.

Особенно важным при этом является возможность управления (при наличии частотно-регулируемого электропривода) режимом работы скважины с целью стабилизации заданной нормы добычи в условиях воздействия как внутренних, так и внешних возмущений. Разработка предложенной системы управле-

\section{СПИСОК ЛИТЕРАТУРЫ}

1. Алаева Н.Н., Томус Ю.Б. Влияние режимов течения восходящих потоков в стволе скважин при автоматизации их работы // Ученые записки Альметьевского государственного нефтяного института. - 2018 - Т. 17. - С. $164-167$.

2. Алаева Н.Н., Томус Ю.Б. Контроль обводненности продукции с целью управления нефтяной добывающей скважиной // Достижения, проблемы и перспективы развития нефтегазовой отрасли: Труды Международной научно-практической конференции. Альметьевск: Изд-во Альметьевского государственного нефтяного института, 2018. - С. 234-238.

3. Измерение обводненности на устье добывающих скважин / Д.Ю. Самойлов, В.В. Самойлов, О.П. Жданов, А.В. Насыбуллин // Экспозиция Нефть Газ. - 2016. - № 3 (49). - С. 85-88.

4. Одиванов В.Л., Курбанов Р.Х., Садыков И.И., Харисов А.Г Программно-аппаратный комплекс «Канал квант» для измерения состава и расхода жидкости, добываемой из нефтяных скважин // Датчики и системы. - 2008. - № 3. - С. 7-12.

5. Алаева Н.Н., Сагадеев Д.Н. К вопросу определения обводненности продукции нефтедобывающих скважин // VIII Научнопрактическая конференция: Труды VIII Межрегиональной научно-практической конференции, посвященной 25-летию Института нефти и газа им. М.С. Гуцериева. - Ижевск, 2018. C. $8-12$.

6. Numerical simulation of gas-liquid two-phase flow in wellbore based on drift flux model / W. Na, X. Chaoyang, M. Yingfeng, L. Gao, L. Anqi // Applied Mathematics and Computation. 2018. - V. 338. - P. 175-191.

7. Djuraev U., Jufar Sh. R., Vasant P. A review on conceptual and practical oil and gas reservoir monitoring methods // Journal of Petroleum Science and Engineering. - 2017. - V. 152. - P. 586-601.

8. РД 153-39.0-920-15. Оптимальный комплекс и периодичность гидродинамических методов контроля за разработкой месторождений ПАО «Татнефть». - Бугульма: ТатНИПИнефть, 2016. - 42 c.

9. Разработка и применение автоматизированной системы управления скважиной с целью повышения нефтеотдачи пластов / Д.Ю. Самойлов, В.В. Самойлов, В.С. Воронков, Ф.А. Галиев // Экспозиция Нефть Газ. - 2015. - № 5 (44). - С. 32-34.

10. Robust technology and system for management of sucker rod pumping units in oil wells / T.A. Aliev, A.H. Rzayev, G.A. Guluyev, T.A. Alizada, N.E. Rzayeva // Mechanical Systems and Signal Processing. - 2018. URL: https://www.sciencedirect.com/science/article/abs/pii/S088832701 7303205 (дата обращения: 19.10.2018). ния процессом нефтедобычи является важным направлением при решении задачи повышения эффективности эксплуатации нефтяных месторождений.

\section{Заключение}

Таким образом, разработано устройство для измерения давлений внутри НКТ и межтрубного пространства нефтедобывающей скважины; представлена математическая модель получения исходных данных для решения основных задач при добыче нефти; предложена система управления процессом нефтедобычи для повышения производительности скважин; реализация разработанного стационарного скважинного прибора в предлагаемой системе управления процессом нефтедобычи обеспечивает точность и быстродействие вывода скважины на стационарный режим работы, его стабилизацию и увеличение отбора добываемой продукции; поставлена и решена задача создания эффективной системы управления процессом нефтедобычи по критерию максимального отбора продукции.

11. Systems and methods for controlling flow from a wellbore annulus // Sealing Technology. 2018. URL: https://www.sciencedirect. com/science/article/pii/S1350478918302915 (дата обращения: 28.11.2018).

12. Pressure and rate transient analysis of artificially lifted drawdown tests using cyclic pump off controllers / I.O. Daniel, H. Manouchehr, A.F. Matthew, A. Mohammad // Journal of Petroleum Science and Engineering. - 2016. - V. 139. - P. 240-253.

13. Torres L.H.S., Schntman L. Sucker-rod pumping system of oil wells: modelling, identification and process control // IFAC Proceedings Volumes. - 2013. - V. 46. - P. 260-265.

14. Режимная эксплуатация глубинного насосного оборудования нефтедобывающих скважин / И.З. Денисламов, А.Р. Камалтдинов, Г.И. Денисламова, Р.Р. Ишбаев // Нефтегазовое дело. 2017. - Т. 15. - № 1. - С. 75-79.

15. Денисламов И.З., Хасаншин В.Р., Денисламова А.И. Оценка системы «пласт-скважина-насос» по данным глубинной телеметрии // Сборник научных трудов: Нефтегазовые технологии и новые материалы. Проблемы и решения. - Уфа: Изд-во ООО «Монография», 2018 - С. 259-262.

16. Современные технические решения для интеллектуальной нефтедобывающей скважины / И.З. Денисламов, Ш.А. Гафаров, Г.И. Денисламова, И.З. Исаев // Нефтепромысловое дело. - 2016. - № 4. - С. 33-37.

17. Govorkov D.A., Solovyev I.G., Fomin V.V. Real-time adaptive observer technology of an oil-well hydrodynamic deep states // 2008 International Conference. Modern Technique and Technologies. - Tomsk, 2008. - P. 100-104.

18. Sagdatullin A.M. Development and modeling of automation and control system of sucker-rod well pump with beam drive // Chemical and Petroleum Engineering. - 2016. - V. 52 - № 1. С. 29-32.

19. Устройство для одновременного измерения давления вне и внутри насосно-компрессорных труб: пат. 2652403 Рос. Федерация. № 2017106690; заявл. 28.02.2017; опубл. 26.04.18, Бюл. № $12 .-11 \mathrm{c}$.

20. Алаева Н.Н., Томус Ю.Б. Система для оперативного управления режимом работы нефтяных добывающих скважин // Достижения, проблемы и перспективы развития нефтегазовой отрасли: Труды Международной научно-практической конференции, посвященной 60-летию высшего нефтегазового образования в Республике Татарстан. - Альметьевск: Изд-во Альметьевского государственного нефтяного института, 2016. - С. 74-76. 


\section{Информация об авторах}

Алаева H.H., старший преподаватель кафедры автоматизации и информационных технологий Альметьевского государственного нефтяного института.

Toмyс Ю.Б., кандидат технических наук, доцент кафедры автоматизации и информационных технологий Альметьевского государственного нефтяного института.

Tуzашова Л.Г., кандидат технических наук, старший преподаватель кафедры автоматизации и информационных технологий Альметьевского государственного нефтяного институтаю 
UDC 681.3

\title{
DEVELOPMENT AND APPLICATION OF PERMANENT DOWNHOLE GAUGE IN OIL PRODUCTION CONTROL SYSTEM
}

\author{
Natalya N. Alaeva', \\ nalaeva@yandex.ru \\ Yuriy B. Tomus ${ }^{1}$, \\ tjub123@rambler.ru \\ Larisa G. Tugashova1, \\ tugashowa.agni@yandex.ru \\ 1 Almetyevsk State Oil Institute, \\ 2, Lenin street, Almetyevsk, 423450, Russia.
}

Relevance of the research is in obtaining reliable measured technological parameters (as a minimum, pressure and density of the produced products) in the well obtained in real time for managing the quality of oil producing well and increasing the efficiency of its operation. The aim of the research is to develop a permanent downhole gauge for measuring pressure at the pump inlet and discharge, inside the tubing and annulus of an oil producing well; compile a mathematical model for obtaining necessary technological parameters to solve the main problems in oil production; apply a permanent downhole gauge in the proposed oil production control system.

Object of the research is oil producing well.

Methods: modeling and evaluation of the proposed oil production control system using the developed permanent downhole gauge for measuring the pressure at several control points of the oil production wells in the program Matlab/Simulink.

Results. The authors have developed the permanent downhole gauge for measuring pressure at the pump inlet and discharge, inside the tubing and annulus of the well. The paper demonstrates its design and the mathematical model for obtaining the necessary technological parameters to solve the main tasks in oil production. The authors proposed the control system using the developed gauge, set the task of creating an effective system for managing oil production and solved it.

Conclusions. A positive result was obtained when simulating oil production control system using the developed downhole gauge for measuring pressure at several control points in an oil producing well using the Matlab/Simulink program. The implementation of the developed permanent downhole gauge in the proposed system for controlling oil production ensures the accuracy and speed of switching the well to the stationary mode of operation, its stabilization and increase in the flow rate.

\section{Key words:}

Oil producing well, pressure measurement, determination of process parameters, control system modeling, oil production.

\section{REFERENCES}

1. Alaeva N.N., Tomus Yu.B. The influence of the upstream flow regimes in the well bore in the automation of their work. Proceedings of the scientific session, scientists of the Almetyevsk State Oil Institute, 2018, vol. 17, pp. 164-167. In Rus.

2. Alaeva N.N., Tomus Yu.B. Kontrol obvodnennosti produktsii s tselyu upravleniya neftyanoy dobivayushchey skvazhinoy [Control of production water cut for management of an oil production well] Dostizheniya, problemi i perspektivy rasvitiva neftegazovoy otrasli. Trudy mezhdunarodnoy nauchno-prakticheskoy konferentsii [Proc. of the International scientific and practical conference. Achievements, problems and prospects of development of the oil and gas industry]. Almetyevsk, 2018. pp. 234-238.

3. Samoilov D.Yu., Samoilov V. V., Zhdanov O. P., Nasybullin A.V. Measurement of water cut at the wellhead of producing wells. Journal Exposition Oil Gas, 2016, no. 3 (49), pp. 85-88. In Rus.

4. Odivanov V.L., Kurbanov R.H., Sadykov I.I., Harisov A.G. Software and hardware complex «Channel quantum» for measuring the composition and flow of liquid extracted from oil wells. Sensors and systems, 2008, no. 3, pp. 7-12. In Rus.

5. Alaeva N.N., Sagadeev D.N. K voprosu opredeleniya obvodnennosti produktsii neftedobivayushchikh skvazhin [On the issue of determining the water content of oil wells]. VIII Nauchnoprakticheskaya konferentsiya. Trudi VIII mezhregionalnoy nauchno-prakticheskoy konferentsii, posvyashchennoy 25-letiyu Instituta nefti i gasa im. M.S. Gutserieva [VIII Scientific and practical conference. Proc. of the VIII Interregional scientific and practical conference dedicated to the $25^{\text {th }}$ anniversary of the M.S. Gutseriev Institute of oil and gas]. Izhevsk, 2018. pp. 8-12.

6. Na W., Chaoyang X., Yingfeng M., Gao L., Anqi L. Numerical simulation of gas-liquid two-phase flow in wellbore based on drift flux model. Applied Mathematics and Computation, 2018, vol. 338, pp. $175-191$.

7. Djuraev U., Jufar Sh. R., Vasant P. A review on conceptual and practical oil and gas reservoir monitoring methods. Journal of $\mathrm{Pe}$ troleum Science and Engineering, 2017, vol. 152, pp. 586-601.

8. RD 153-39.0-920-15. Optimalny kompleks i periodichnosty gidrodinamicheskikh metodov kontrolya za razrabotkoy $P A O$ «Tatneft» [Guidance Document 153-39.0-920-15. Optimum range and frequency of hydrodynamic controls on the development of PJSC «Tatneft»]. Bugulma, TatNIPIneft Publ., 2016. 42 p.

9. Samoilov D.Yu., Samoilov V.V., Voronkov V.S., Galiyev F.A. Development and application of automated well control system to improve oil recovery. Journal Exposition Oil Gas, 2015, no. 5, pp. 32-34. In Rus.

10. Aliev T.A., Rzayev A.H., Guluyev G.A., Alizada T.A., Rzayeva N.E. Robust technology and system for management of sucker rod pumping units in oil wells. Mechanical Systems and Signal Processing, 2018. Available at: https://www.sciencedirect.com/science/article/ abs/pii/S0888327017303205 (accessed 19 October 2018).

11. Systems and methods for controlling flow from a wellbore annulus. Sealing Technology, 2018. Available at: https://www.sciencedirect. com/science/article/pii/S1350478918302915 (accessed 28 November 2018).

12. Daniel I.O., Manouchehr H., Matthew A.F., Mohammad A. Pressure and rate transient analysis of artificially lifted drawdown tests using cyclic pump off controllers. Journal of Petroleum Science and Engineering, 2016, vol. 139, pp. 240-253.

13. Torres L.H.S., Schntman L. Sucker-rod pumping system of oil wells: modelling, identification and process control. IFAC Proceedings Volumes, 2013, vol. 46, pp. 260-265. 
14. Denislamov I.Z., Kamaletdinov A.R., Danilova G.I. Ishbaev R.R. Modal exploitation of the deep pump equipment of oil wells. Oil industry, 2017, vol. 15, no. 1, pp. 75-79. In Rus.

15. Denislamov I.Z., Khasanshin V.R., Denislamova A.I. Otsenka sistemy «plast-skvazhina-nasos» po dannym glubinnoy telemetrii [Evaluation of the system «formation-well-pump» according to the deep telemetry]. Sbornik nauchnukh trudov: Neftegazovye tekhnologii i novye materialy. Peolblemy $i$ resheniya [Collection of scientific works: Oil and gas technologies and new materials. Problems and solutions]. Ufa, Monografiya Publ., 2018. pp. 259-262.

16. Denislamov Z.I., Gafarov S.A., Danilova G.I., Isaev I.Z. Modern technical solutions for intelligent oil wells. Oilfield business, 2016, no. 4, pp. 33-37. In Rus.

17. Govorkov D.A., Solovyev I.G., Fomin V.V. Real-time adaptive observer technology of an oil - well hydrodynamic deep states. In ternational Conference. Modern Technique and Technologies. Tomsk, 2008. pp. 100-104.

18. Sagdatullin A.M. Development and modeling of automation and control system of sucker-rod well pump with beam drive. Chemical and Petroleum Engineering, 2016, vol. 52, no. 1, pp. 29-32.

\section{Information about the authors}

Natalya N. Alaeva, senior lecturer, Almetyevsk State Oil Institute.

Yuriy B. Tomus, Cand. Sc., associate professor, Almetyevsk State Oil Institute.

Larisa G. Tugashova, Cand. Sc., senior lecturer, Almetyevsk State Oil Institute.
19. Alaeva N.N., Tomus Yu.B., Sitdikova I.P., Temnikova L.I. Ustroystvo dlya odnovremennogo izmereniya davleniya vne $i$ vnutri nasosno-kompressornykh trub [Device for simultaneous measurement of pressure outside and inside the tubing]. Patent RF, no. 2652403, 2018.

20. Alaeva N.N., Tomus Yu.B. Sistema dlya operativnogo upravleniya rezhimom raboty neftyanykh dobyvayushchikh skvazhin [System for operational management of oil production wells]. Dostizheniya, problemy $i$ perspektivy razvitiya neftegasovoy otrasli. Trudy mezhdunarodnoy nauchno-prakticheskoy konferentsii, posvyachennoy 60-letiyu vysshego neftegazovogo obrazovaniya $v$ Respublike Tatarstan [Proc. of the International scientific and practical conference devoted to the $60^{\text {th }}$ anniversary of higher oil and gas education in the Republic of Tatarstan. Achievements, problems and prospects of development of the oil and gas industry]. Almetyevsk, 2016. pp. 74-76.

Received: 2 December 2019. 